\title{
Variation Within and Between Vitis spp. for Foliar Resistance to the Downy Mildew Pathogen Plasmopara viticola
}

\author{
Lance Cadle-Davidson, United States Department of Agriculture-Agricultural Research Service, Grape Genetics \\ Research Unit, Geneva, NY 14456
}

\begin{abstract}
Cadle-Davidson, L. 2008. Variation within and between Vitis spp. for foliar resistance to the downy mildew pathogen Plasmopara viticola. Plant Dis. 92:1577-1584.

To complement existing control strategies, grape growers in humid climates desire cultivars with resistance to downy mildew caused by Plasmopara viticola. Numerous disease resistance screens of diverse Vitis germplasm have been conducted previously to identify downy mildew resistance; however, ratings of named cultivars were inconsistent and identities of resistant individuals in wild species were not typically provided. Inconsistencies among previous studies could be due to race-specific resistance. In the current study, controlled inoculations of two single isolates onto two leaf ages of 883 Vitis accessions were used and these results compared with natural infection in a fivefold replicated vineyard of 80 Vitis accessions in 2006 and 2007. Of the accessions rated in both assays, $16.2 \%$ were resistant to a single isolate but susceptible in the vineyard. Otherwise, there was good correlation of ratings between the field assay and the rating of older leaves ( $r=0.62$ to 0.71 ). Five accessions from Vitis cinerea, V. labrusca, and Vitis $\times$ champinii averaged zero severity in both vineyard years, yet some individuals of $V$. cinerea and V. labrusca were moderately or highly susceptible in the field. Similarly, although significant differences in mean severity separated V. vinifera, Vitis hybrid, V. riparia, and V. labrusca for single-isolate inoculations (from susceptible to resistant), notable intraspecies variation was identified for all well-represented species. Resistant individuals were identified in most species with the prominent exceptions of $V$. vinifera and $V$. acerifolia. Single-isolate, detached-leaf resistance ratings in 2006 corresponded well (94.6\%) to 2007 ratings using a separate isolate collected from the same vineyard. Categorizing the ratings for this and previous studies, ratings infrequently corresponded among previous studies (31.9\%) as well as between previous studies and the current single-isolate $(34.9 \%)$ or vineyard (46.4\%) ratings. These results highlight important factors for downy mildew resistance screens: leaf age, pathogen genotype, and host species and accession. The results further underscore the importance to breeders of uniform testing in multiple environments.
\end{abstract}

Vitis vinifera grapevines are highly susceptible to downy mildew caused by the host-specific oomycete Plasmopara viticola. In humid climates like New York, where the unchecked pathogen will defoliate vines and destroy young fruit clusters, growers depend upon multiple fungicide applications for disease management. However, management of $P$. viticola by fungicides is tenuous, because the pathogen has repeatedly overcome a broad range of previously effective fungicides (9). To complement chemical disease control (31) and predictive models (13), diseaseresistant interspecific hybrids have been developed to combine disease resistance with the production of high-quality fruit (1). Molecular markers associated with

Corresponding author: L. Cadle-Davidson

E-mail: Lance.CadleDavidson@ars.usda.gov

Accepted for publication 18 July 2008.

doi:10.1094/PDIS-92-11-1577

This article is in the public domain and not copyrightable. It may be freely reprinted with customary crediting of the source. The American Phytopathological Society, 2008. some downy mildew resistance genes have been identified to facilitate additional introgression of resistance $(7,8,17,30)$.

Numerous germplasm screens have been conducted in Vitis spp. to identify accessions resistant to downy mildew $(3,5,6,18-$ $20,23,25,26,29)$. In those studies that screened multiple accessions per species, variation in resistance was identified not only between but also sometimes within species $(10,26,29)$. In spite of these findings, Vitis spp. are often generalized as being more or less resistant without characterizing the resistance of accessions within each species $(5,6,18,19,21,25)$. Some cultivars were screened in multiple studies and their resistance ratings frequently failed to match. For example, Vitis hybrid 'Athens' was rated resistant (19), moderately susceptible (5), and susceptible $(3,25)$, and Vitis hybrid 'Isabella' was rated resistant $(3,19)$, moderately resistant (6), moderately susceptible (5), and susceptible (25). These results highlight the need to control environment and pathogen source in grape downy mildew resistance screens and to ensure cultivar identity. However, one cultivar, Vitis hybrid 'Concord,' was consistently resistant $(6,19)$ or moderately resistant (3) across studies and, thus, appears to have durable, broad-spectrum resistance.

Given the long lifespan of grapevines in commercial vineyards and the high cost of their establishment, durable disease resistance is a desirable trait for cultivars. Race-specific resistance has been shown in other host-specific downy mildew pathosystems, including lettuce (32), Arabidopsis (11), and sunflower (24), and this form of resistance has been shown to be overcome by virulent isolates in each pathosystem. Although race-specific resistance has not previously been demonstrated in Vitis spp., isolates of $P$. viticola vary in their quantitative virulence on different cultivars of Vitis (12).

Novel sources and mechanisms of disease resistance can be found among the genetically diverse accessions maintained by grapevine germplasm repositories (22). There are a number of repositories around the world and, in the United States, two United States Department of AgricultureAgricultural Research Service (USDAARS) locations maintain a combined total of over 4,100 Vitis accessions. V. vinifera and cold-sensitive species are among the major holdings at the National Clonal Germplasm Repository near Davis, CA, whereas the cold-hardy species are maintained at the Plant Genetic Resources Unit (PGRU) in Geneva, NY.

One limitation of screening for disease resistance in a Vitis germplasm repository is that the accessions are maintained as living grapevines, and the health status of the vines is critical to their long-term preservation. Therefore, screening for resistance in the repository vineyard is not routinely possible. In this study, two methods were tested for screening diverse accessions of Vitis spp. for resistance to downy mildew. In the first, a subset of the cold-hardy germplasm collection was vegetatively propagated, established in a vineyard, and natural epidemics of downy mildew were allowed to progress. In the second screen, leaves were directly collected from the germplasm repository, surface sterilized, and inoculated in petri dishes using a single isolate.

\section{MATERIALS AND METHODS}

Plant material for natural infection in the vineyard. In all, 80 accessions from 14 Vitis spp. and 35 interspecific hybrids were selected for vegetative propagation 
Table 1. Downy mildew severity on accessions of Vitis species for natural infections in 2006 and 2007 and for two developmental stages of detached leaves inoculated with a single isolate

\begin{tabular}{|c|c|c|c|c|c|c|}
\hline \multirow[b]{2}{*}{$\mathbf{P I}^{\mathbf{w}}$} & \multirow[b]{2}{*}{ Accession name ${ }^{x}$} & \multirow[b]{2}{*}{ Vitis spp. ${ }^{\mathbf{y}}$} & \multicolumn{4}{|c|}{ Average disease severity $^{v}$} \\
\hline & & & 2006 Vineyard & 2007 Vineyard & Younger leaf & Older leaf \\
\hline 588442 & & V. acerifolia & 6 & 3 & 0 & 5 \\
\hline 237621 & Jaeger & V. aestivalis & 3 & 4 & 5 & 4 \\
\hline 483130 & Rem NE 4 & V. aestivalis & 4 & 5 & 0 & 7 \\
\hline 483137 & Rem 46-77 & V. aestivalis & 0 & 1 & 0 & 2 \\
\hline 588382 & & V. amurensis & 2 & 0 & nd & nd \\
\hline 588629 & & V. amurensis & 2 & 0 & nd & 0 \\
\hline 588634 & & V. amurensis & 4 & 0 & nd & 0 \\
\hline 588186 & Ill 58 & $V$. cinerea & 3 & 1 & 0 & 0 \\
\hline 588210 & B $65-7$ & V. cinerea & 2 & 0 & nd & 8 \\
\hline 588220 & B 55 & $V$. cinerea & 0 & 0 & 0 & 0 \\
\hline 588222 & C-66-7 & V. cinerea & 0 & 0 & 0 & 0 \\
\hline N/A & $44-53 \mathrm{M}$ & Vitis hybrid & 1 & 3 & 2 & 2 \\
\hline N/A & Schwarzmann & Vitis hybrid & 3 & 7 & 2 & 4 \\
\hline 157518 & Villard Blanc (Seyve-Villard 12.375) & Vitis hybrid & 0 & 1 & nd & nd \\
\hline 175494 & Cascade (Seibel 13.053) & Vitis hybrid & 5 & 6 & 2 & $1 *$ \\
\hline 181481 & Vignoles (Ravat 51) & Vitis hybrid & 6 & 8 & 7 & 7 \\
\hline 181642 & Bertille Seyve 872 & Vitis hybrid & 2 & 7 & 6 & 5 \\
\hline 279899 & Kober 5BB & Vitis hybrid & 4 & 5 & 2 & 2 \\
\hline 313922 & Tarnau & Vitis hybrid & 0 & 5 & 0 & 3 \\
\hline 588070 & Catawba & Vitis hybrid & 6 & 3 & $0 *$ & $0 *$ \\
\hline 588078 & Delaware & Vitis hybrid & 7 & 9 & $0 *$ & $0 *$ \\
\hline 588094 & Joannes Seyve 23.416 & Vitis hybrid & 3 & 9 & 2 & 4 \\
\hline 588095 & Himrod & Vitis hybrid & 6 & 7 & nd & 4 \\
\hline 588107 & Marechal Foch (Kuhlmann 188-2) & Vitis hybrid & 5 & 3 & 5 & 3 \\
\hline 588111 & Golden Muscat & Vitis hybrid & 5 & 6 & 4 & 5 \\
\hline 588113 & Steuben & Vitis hybrid & 7 & 3 & nd & 6 \\
\hline 588180 & Millardet et de Grasset 101-14 & Vitis hybrid & 3 & 2 & 2 & 3 \\
\hline 588196 & Mills & Vitis hybrid & 7 & 5 & $0 *$ & $0 *$ \\
\hline 588207 & Isabella & Vitis hybrid & 6 & 4 & nd & nd \\
\hline 588234 & Jaeger 70 & Vitis hybrid & 3 & 2 & nd & nd \\
\hline 588279 & Goethe & Vitis hybrid & 5 & 8 & nd & nd \\
\hline 588303 & Clinton & Vitis hybrid & 0 & 6 & nd & 6 \\
\hline 588315 & Noah & Vitis hybrid & 4 & 5 & 0 & 7 \\
\hline 588319 & Diana & Vitis hybrid & 5 & 4 & 0 & 3 \\
\hline 588327 & Ill 547-1 & Vitis hybrid & 3 & 1 & 0 & 0 \\
\hline 588397 & & Vitis hybrid & 4 & 2 & 3 & 3 \\
\hline 588405 & & Vitis hybrid & 4 & 7 & 4 & 3 \\
\hline 588419 & & Vitis hybrid & 4 & 3 & $0 *$ & $0 *$ \\
\hline 588488 & NY 65.592.1 & Vitis hybrid & 0 & 4 & 7 & 4 \\
\hline 588623 & Taylor & Vitis hybrid & 6 & 10 & 0 & 5 \\
\hline 588627 & 7623 & Vitis hybrid & 6 & 8 & 0 & 4 \\
\hline 588693 & Ivan & Vitis hybrid & 6 & 5 & 1 & 6 \\
\hline 594334 & Baco Noir (Baco 1) & Vitis hybrid & 8 & 8 & 8 & 4 \\
\hline 594336 & Seibel 29 & Vitis hybrid & 7 & 6 & 5 & 3 \\
\hline 594346 & Karmrajut & Vitis hybrid & nd & 9 & 3 & 7 \\
\hline 594349 & Alexander & Vitis hybrid & 4 & 7 & $0 *$ & $1 *$ \\
\hline 588128 & Vergennes & V. labrusca & 6 & 6 & 2 & $1 *$ \\
\hline 588145 & GBC 12 & V. labrusca & 0 & 0 & 0 & 0 \\
\hline 588165 & Alba & V. labrusca & 2 & 0 & 0 & 0 \\
\hline 588173 & GBC 2 & V. labrusca & 2 & 1 & 0 & 0 \\
\hline 588277 & Jersey Muscat & V. labrusca & 0 & 0 & 0 & 1 \\
\hline 588307 & Champagne & V. labrusca & 2 & 0 & 0 & 0 \\
\hline 588583 & Grem-4 & V. labrusca & 2 & 0 & nd & 0 \\
\hline 588658 & Lutie & V. labrusca & 2 & 1 & nd & 3 \\
\hline 588201 & $\ldots$ & V. palmata & 3 & 1 & 1 & 3 \\
\hline 588233 & Cache 8 & $V \cdot$ palmata & 2 & 1 & 1 & 1 \\
\hline 588054 & Iowa 7 & $V$. riparia & 1 & 4 & 1 & 4 \\
\hline 588259 & 37 & V. riparia & 6 & 4 & $0 *$ & $0 *$ \\
\hline 588262 & 89 & V. riparia & 5 & 6 & 0 & 4 \\
\hline 588435 & $2 \mathrm{~F}$ & V. riparia & 6 & 3 & $1 *$ & $0 *$ \\
\hline 588438 & $\ldots$ & V. riparia & 4 & 1 & 0 & 1 \\
\hline
\end{tabular}

v Average severity of downy mildew across all replicates was rated in 2006 and 2007 for each accession naturally infected in the vineyard, and in 2006 and 2007 for each accession artificially inoculated with two isolates for younger and older leaves. Older leaves were the fourth fully expanded leaf in each year whereas younger leaves were the second fully-expanded leaf in 2006 only; nd = not determined due to all replicate leaves dying prior to disease ratings and * denotes instances of low severity on detached leaves where that same accession was susceptible to natural inoculum.

${ }^{\mathrm{w}} \mathrm{PI}=$ plant introduction number, a unique identifier for each accession in the Germplasm Resources Information Network (GRIN) database, where PI is linked with additional information related to that accession (http://www.ars-grin.gov/npgs/index.html). N/A: Schwarzmann and 44-53M do not have PI numbers and are not distributed by ARS-PGRU but are widely available as commercial rootstocks.

$x$ Name listed for each accession, provided in the GRIN database.

y Species listed for each accession, provided in the GRIN database. Vitis interspecific hybrids are listed as Vitis hybrid.

${ }^{\mathrm{z}}$ Overall averages were calculated based on ratings for each leaf rated. 
Table 1. (continued from preceding page)

\begin{tabular}{|c|c|c|c|c|c|c|}
\hline \multirow[b]{2}{*}{$\mathbf{P I}^{\mathbf{w}}$} & \multirow[b]{2}{*}{ Accession name ${ }^{x}$} & \multirow[b]{2}{*}{ Vitis spp..$^{\mathrm{y}}$} & \multicolumn{4}{|c|}{ Average disease severity } \\
\hline & & & 2006 Vineyard & 2007 Vineyard & Younger leaf & Older leaf \\
\hline 588439 & $\ldots$ & V. riparia & 2 & 2 & 0 & 3 \\
\hline 588440 & $\ldots$ & V. riparia & 4 & 1 & 0 & 2 \\
\hline 588483 & Rem NE 21 & V. riparia & 3 & 6 & 0 & 3 \\
\hline 588565 & Grem & V. riparia & 1 & 3 & 1 & 2 \\
\hline 594344 & Zumbrunnen & V. riparia & 3 & 4 & 0 & 3 \\
\hline 594348 & C-166-043 & V. romanetii & 0 & 10 & nd & $1^{*}$ \\
\hline 588146 & $\mathrm{R}-66-4$ & V. rupestris & 1 & 2 & 0 & 2 \\
\hline 588160 & B 38 & V. rupestris & nd & 2 & 0 & 1 \\
\hline 588223 & R-65-43 & V. rupestris & 0 & 1 & 0 & 4 \\
\hline 588224 & R-65-44 & $V$. rupestris & 2 & 1 & 0 & 3 \\
\hline 588335 & $\ldots$ & V. rupestris & 3 & 2 & 7 & 6 \\
\hline 588454 & $\ldots$ & V. rupestris & 4 & 6 & nd & $0^{*}$ \\
\hline 588133 & GBC 5 & V. vulpina & 4 & 4 & 3 & 5 \\
\hline 588142 & GBC 28 & $V$. vulpina & 0 & 1 & 1 & 4 \\
\hline 588679 & $\ldots$ & V. vulpina & 1 & 0 & 1 & 1 \\
\hline 588392 & $\ldots$ & Vitis $\times$ andersonii & 2 & 3 & 0 & 5 \\
\hline 588371 & $\ldots$ & Vitis $\times$ champinii & 0 & 0 & nd & nd \\
\hline 588149 & $\ldots$ & Vitis $\times$ doaniana & 2 & 0 & 0 & 3 \\
\hline 588257 & $\ldots$ & Vitis $\times$ novae-angliae & 7 & 6 & 0 & 3 \\
\hline Overall averages $^{\mathrm{z}}$ & $\ldots$ & $\ldots$ & 3.2 & 3.5 & 1.4 & 2.2 \\
\hline
\end{tabular}

from the USDA-ARS, PGRU cold-hardy grape collection. Two- and three-year-old, own-rooted grapevines were planted in an experimental vineyard in Fredonia, NY, in June 2005 with $1.8-\mathrm{m}$ spacing between vines and with five replicate blocks in a randomized complete block design. Standard production practices for insect, deer, and weed control were followed but no fungicides were applied in 2006 and 2007.

Plant material for single-isolate inoculation of detached leaves. Grapevines in the USDA-ARS, PGRU grape collection are maintained in the field as own-rooted vines at the McCarthy South vineyard, Geneva, NY. Each accession is represented by two adjacent, replicate, own-rooted vines planted with $1.8-\mathrm{m}$ within-row spacing using a three-wire trellis, cane-pruned and trained to the Umbrella Kniffin system. Each accession has a unique plant introduction (PI) number listed in the USDA-ARS Germplasm Resources Information Network (GRIN) database (28). Each year, standard production practices were followed for the Finger Lakes region, with vines being sprayed at 2-week intervals for the management of downy mildew and powdery mildew.

Downy mildew isolation. $P$. viticola isolates Pv05-01 and Pv07-03 were isolated from a prebloom cluster of Vitis hybrid 'Chancellor' collected in June 2005 and 2007, respectively, at the Robbins farm, Geneva, NY. Sporulation was induced from the epinastic cluster by incubating it overnight in a moist chamber. A single sporangiophore branch was transferred by forceps to a $10-\mu l$ water droplet on the abaxial surface of a surfacesterilized, detached leaf of a $V$. vinifera 'Riesling' seedling placed on $1 \%$ water agar. A single sporangiophore branch from the resulting lesion was again transferred to produce each isolate. Inoculum was subsequently maintained on leaves of Riesling or $V$. vinifera 'Chardonnay' seedlings by bulk transfer every 6 to 14 days. Sporangia were collected from the leaf surface by spraying with distilled water and collecting the spore suspension in a vessel. The suspension was adjusted to $5 \times 10^{4}$ sporangia/ml and sprayed onto surfacesterilized, detached leaves.

Leaf collection for single-isolate inoculations. Twelve days after each biweekly fungicide spray application, replicate leaves were collected for the experiment, with tissue collection initiating a biweekly routine of protocols. In 2006, 883 accessions were inoculated with Pv05-01 and, in 2007, a subset of 205 accessions was inoculated with Pv07-03 to confirm results. For each accession, resistance was characterized on the northern vine only of each pair, except when that vine was missing or damaged, in which case the other replicate vine was sampled. Two shoots were arbitrarily selected and replicates of the second and fourth fully expanded leaves (2006) or the fourth leaf (2007) from each shoot were removed, stacked in a standard order, and placed into a flexible plastic compact disc (CD) sleeve labeled with the accession number. Each CD sleeve had nine holes punched into it to facilitate wetting during subsequent leaf sterilization and washing. Leaves were collected early in the day before air temperatures reached $29^{\circ} \mathrm{C}$, placed over ice within $15 \mathrm{~min}$ of collection, and maintained at 4 to $8^{\circ} \mathrm{C}$ until further sample processing within $24 \mathrm{~h}$.

Surface sterilization, plating, and inoculation. Leaves in $C D$ sleeves were submersed into calcium hypochlorite at $0.88 \mathrm{~g} /$ liter for $2 \mathrm{~min}$ with agitation and then washed three times in sterile distilled water for $5 \mathrm{~min}$ each. The leaves were removed from each $\mathrm{CD}$ sleeve, still in their original stacking order, and plated abaxial side up onto 100-by-15-mm petri dishes containing $18 \mathrm{ml}$ of $1 \%$ water agar amended with natamycin (Haorui PharmaChem, Edison, NJ) at $0.01 \mathrm{~g} /$ liter. Each petri dish was prelabeled to track the accession, shoot replicate, and leaf age. Residual water was removed from each leaf surface using a sterile Kimwipe (Kimberly Clark, Dallas).

After preparation of a complete batch, inoculation was conducted using isolate Pv05-01 or Pv07-03. Spore suspensions were made as described above and concentration adjusted to $5 \times 10^{4}$ sporangia $/ \mathrm{ml}$. Leaves were inoculated by bulk transfer, then placed into a dark $20 \pm 2^{\circ} \mathrm{C}$ growth chamber overnight. The leaf surface was once again dried with a sterile Kimwipe and petri dishes were placed in a $20 \pm 2{ }^{\circ} \mathrm{C}$ growth chamber with a 12-h photoperiod.

Downy mildew disease ratings and statistical analyses. Detached leaves were inspected at up to $\times 10$ magnification for downy mildew sporulation at 9 days post inoculation. Sporulation was rated based on the percentage of leaf area with visible sporangia in $10 \%$ increments and recorded on a 0 -to- 10 scale, where $0=$ no visible sporangia and $10=100 \%$ coverage. For field ratings, disease severity was rated based on the most heavily sporulating leaf for a given vine, which was typically within $0.5 \mathrm{~m}$ of the ground, using the same 0-to-10 scale. Correlation coefficients for accessions tested in the vineyard and fourth-leaf, single-isolate assays were calculated for disease severity using Minitab 15 (State College, PA). Tukey's multiple comparisons analysis was used to compare relative susceptibility of species for the fourth-leaf, single-isolate severity data, based on a mixed model in JMP 7 (SAS Institute, Cary, NC). Predictors included "year" and "species," with the ran- 
dom variable "PI" for each accession and the response variable "severity." Species represented by more than three accessions were included in the model. To compare younger and older leaves, a mixed model with the same response variable and predictors was used in addition to the predictor "leaf age," and each predictor was significant at $P<0.0001$ in both models. For cross-study comparisons, ratings were

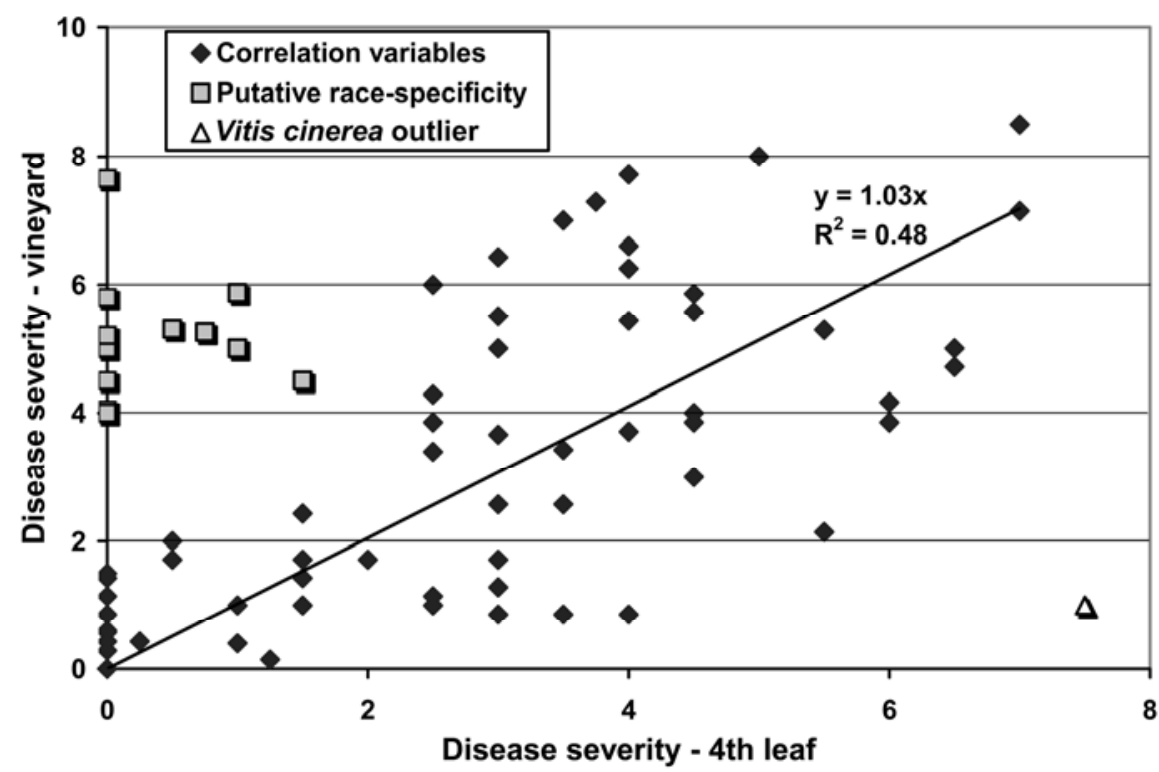

Fig. 1. Correlation of downy mildew severity ratings, comparing single isolate inoculations (x-axis) to natural infection in a vineyard ( $y$-axis). Twelve of the accessions were resistant (average severity $<1.5$ ) to the single-isolate inoculation but at least moderately susceptible (average severity $\geq 2.5$ ) to naturally occurring isolates in the vineyard and are plotted separately (gray square). A single accession of Vitis cinerea (PI 588210) was highly resistant in the vineyard but susceptible to detached-leaf inoculation (open triangle). The $R^{2}$ value and regression formula with forced-zero intercept are based on the remaining data points (filled rhombus). categorized as resistant (R), moderate (M), or susceptible (S). Ratings corresponded when an accession was rated in the exact same category in two studies. Correspondence was expressed as a percentage of the total comparisons made.

\section{RESULTS}

Variation in natural downy mildew severity within and between Vitis spp. Eighty Vitis accessions were rated for natural downy mildew severity in a no-spray vineyard. The average severity in 2006 was 3.2 , with a range of 0 to 8 ; in 2007 , it was 3.5 , with a range of 0 to 10 . The frequency of escapes (no disease on an entire susceptible vine) was estimated. Of the moderately susceptible and susceptible accessions (average severity $\geq 2.5$ ), no sporulating downy mildew was detected for 44 of 326 (13.5\%) replicate vines.

Species varied in their relative susceptibility. The lowest natural severity was observed across accessions of $V$. cinerea and in Vitis $\times$ champinii (Table 1), which is thought to be a natural hybrid of $V$. rupestris and $V$. candicans. Only three accessions (PI 588220, 588222, and 588371), two of $V$. cinerea and one of Vitis $\times$ champinii, were completely free from downy mildew sporulation on all vines in both years; in addition, two accessions of V. labrusca (PI 588145 and 588277) averaged zero severity in both years. The highest natural severity was observed across

Table 2. Variation in resistance to downy mildew within and between Vitis spp., as quantified by inoculation of detached leaves with a single isolate of Plasmopara viticolat

\begin{tabular}{|c|c|c|c|c|c|c|}
\hline \multirow[b]{2}{*}{ Vitis spp. ${ }^{\mathrm{w}}$} & \multicolumn{3}{|c|}{ Younger leaves ${ }^{u}$} & \multicolumn{3}{|c|}{ Older leaves $^{v}$} \\
\hline & Avg. severity ${ }^{x}$ & Range $^{y}$ & No. rated $^{\mathrm{z}}$ & Avg. severity ${ }^{x}$ & Range $^{\mathrm{y}}$ & No. rated $^{\mathrm{z}}$ \\
\hline$V$. vinifera & 4.7 & $1.5-8.0$ & 13 & $5.5 \mathrm{a}$ & $0.0-6.5$ & 17 \\
\hline Vitis $\times$ andersonii & 0.0 & $0.0-0.0$ & 1 & $4.5-$ & $4.5-4.5$ & 1 \\
\hline Vitis hybrid & 2.1 & $0.0-9.3$ & 565 & $3.3 \mathrm{~b}$ & $0.0-9.0$ & 617 \\
\hline V. acerifolia & 1.3 & $0.0-5.0$ & 11 & $3.3 \mathrm{bc}$ & $0.5-5.0$ & 12 \\
\hline Vitis $\times$ doaniana & 0.0 & $0.0-0.0$ & 1 & $3.0-$ & $3.0-3.0$ & 1 \\
\hline Vitis $\times$ novae-angliae & 0.0 & $0.0-0.0$ & 1 & $3.0-$ & $3.0-3.0$ & 1 \\
\hline$V$. piasezkii & 3.0 & $1.0-5.0$ & 2 & $2.8-$ & $1.5-4.0$ & 2 \\
\hline V. riparia & 0.9 & $0.0-6.5$ & 61 & $2.5 \mathrm{c}$ & $0.0-7.0$ & 61 \\
\hline Vitis spp. & 1.5 & $0.0-5.5$ & 18 & $2.4 \mathrm{c}$ & $0.0-6.5$ & 24 \\
\hline V. rupestris & 1.9 & $0.0-7.0$ & 27 & $2.3 \mathrm{~cd}$ & $0.0-5.5$ & 27 \\
\hline V. palmata & 0.7 & $0.0-2.0$ & 5 & $2.0 \mathrm{bcd}$ & $0.0-3.5$ & 5 \\
\hline Vitis $\times$ champinii & 1.8 & $0.0-3.0$ & 3 & $2.0-$ & $0.0-4.0$ & 3 \\
\hline V. aestivalis & 0.7 & $0.0-4.5$ & 8 & $1.5 \mathrm{~cd}$ & $0.0-6.5$ & 8 \\
\hline Ampelopsis & 1.0 & $1.0-1.0$ & 1 & $1.5-$ & $1.5-1.5$ & 1 \\
\hline V. vulpina & 1.0 & $0.0-4.0$ & 14 & $1.4 \mathrm{~cd}$ & $0.0-5.0$ & 14 \\
\hline V. amurensis & 1.5 & $0.0-7.0$ & 11 & $1.1 \mathrm{~cd}$ & $0.0-5.0$ & 12 \\
\hline V. coignetiae & 0.0 & $0.0-0.0$ & 4 & $1.1 \mathrm{bcd}$ & $0.0-5.5$ & 5 \\
\hline$V$. cinerea & 0.1 & $0.0-1.5$ & 28 & $0.8 \mathrm{~d}$ & $0.0-7.5$ & 30 \\
\hline V. labrusca & 0.3 & $0.0-8.5$ & 40 & $0.5 \mathrm{~d}$ & $0.0-5.5$ & 42 \\
\hline Grand total & 1.8 & $0.0-9.3$ & 814 & 2.9 & $0.0-9.0$ & 883 \\
\hline
\end{tabular}

${ }^{t}$ Species are listed in order of decreasing severity ratings on older leaves. For fourth-leaf data, Tukey's multiple comparisons analysis was used; groupings with the same letter were not significantly different at $\alpha=0.05$. Species represented by three or fewer accessions were not included in the analysis and are denoted by -.

" Includes the second fully expanded leaf in 2006.

${ }^{v}$ Includes the fourth fully expanded leaf in 2006 and 2007.

${ }^{\mathrm{w}}$ Species listed for each accession, provided in the Germplasm Resources Information Network database (http://www.ars-grin.gov/npgs/index.html). Vitis interspecific hybrids are listed as Vitis hybrid. One accession of Ampelopsis brevipedunculata, a relative of Vitis in the Vitaceae, was included in the study.

$\mathrm{x}$ Average disease severity, calculated by averaging all rated leaves for that category.

${ }^{y}$ Range of average severity of each accession in a given species.

${ }^{\mathrm{z}}$ Number of accessions rated. The discrepancy between numbers rated for younger and older leaves is due to higher mortality of younger leaves in petri dishes. 
accessions of interspecific hybrids as well as in $V$. acerifolia and in Vitis $\times$ novaeangliae, considered to be the spontaneous hybrid of $V$. labrusca and $V$. riparia. Three interspecific hybrids (PI 588078, 588623, and 594334) were consistently susceptible, with leaf samples of every vine in both years rated 5 or higher.

Variation was also partitioned within species and between years. Within species, variation was pronounced in all species represented by five or more accessions ( $V$. labrusca, V. riparia, and V. rupestris) as well as in $V$. aestivalis (three accessions) and $V$. vulpina (three accessions) (Table 1). To assess year-to-year variability, average severity ratings for each accession were compared between 2006 and 2007, and 68 of the 78 accessions screened in both years had similar ratings (within three gradations). In all cases but two, this betweenyear disparity occurred due to higher disease severity in 2007.

Correlation of natural and singleisolate, detached-leaf downy mildew severity. Eighty accessions were tested for downy mildew severity using both natural infection and inoculation of detached leaves. For six of the accessions, all detached-leaf replicates died before rating; leaves of these accessions died on the water agar media whether inoculated or not. Of the remaining 74 accessions, 12 $(16.2 \%)$ were resistant (average singleisolate severity $<1.5$ ) to the single-isolate inoculation but at least moderately susceptible (average vineyard severity $\geq 2.5$ ) to naturally occurring isolates in the vineyard (Table 1; Fig. 1). The remaining accessions

Table 3. Number of resistant accessions identified within species for this study (C-D) and Staudt and Kassemeyer (26)

\begin{tabular}{lcc}
\hline & \multicolumn{2}{c}{$\begin{array}{c}\text { Proportion of accessions } \\
\text { resistant (resistant/total) }\end{array}$} \\
\cline { 2 - 3 } Species & Staudt $^{\mathbf{y}}$ & C-D $^{\mathbf{z}}$ \\
\hline Vitis acerifolia & $0 / 10$ & $0 / 11$ \\
V. aestivalis & $0 / 13$ & $5 / 8$ \\
V. amurensis & $0 / 2$ & $5 / 11$ \\
Vitis $\times$ champinii & $0 / 5$ & $1 / 3$ \\
V. cinerea & $3 / 7$ & $21 / 28$ \\
Vitis $\times$ doaniana & $1 / 5$ & $0 / 1$ \\
V. palmata & $1 / 5$ & $2 / 5$ \\
V. riparia & $1 / 2$ & $14 / 61$ \\
V. rupestris & $0 / 3$ & $9 / 27$ \\
V. vulpina & $0 / 9$ & $9 / 14$ \\
Vitis hybrid & $0 / 8$ & $119 / 565$ \\
\hline
\end{tabular}

${ }^{\mathrm{y}}$ As provided in Table 1 of Staudt and Kassemeyer (26), with $V$. solonis being grouped with $V$. acerifolia and $V$. rubra with $V$. palmata here. Sevenfold replicated leaf discs were inoculated with a population $(\mathrm{H}$. H. Kassemeyer, personal communication) of Plasmopara viticola collected in Freiburg, Germany. Resistant accessions, defined by the lack of sporangiophores at 5 days post inoculation, were listed.

${ }^{z}$ Data from the current study, based on average disease severity for accessions inoculated with a single-isolate. Any accession with severity $<1.5$ on both second and fourth fully expanded leaves was categorized as resistant. had moderate correlation between disease severity on younger detached leaves and the average vineyard rating across both years $(r=0.37)$ and good correlation between disease severity on older detached leaves and the average vineyard rating across both years $(r=0.62)$. One accession ( $V$. cinerea, PI 588210) was highly resistant in the vineyard (average severity $=0.7$ ) but susceptible to detached-leaf inoculation (average severity $=7.5$ ); removal of this outlier resulted in a correlation of $r=0.71$.

For the same 74 accessions, the frequency of escapes (no disease on susceptible accessions) was estimated for the fourth leaf. Of the moderately susceptible accessions (average severity $\geq 1.5$ in the single isolate screen), 17 of 115 (14.8\%) inoculated leaves had no sporulating downy mildew. Therefore, these estimates suggest that a susceptible accession could escape infection on two replicate leaves, but likely at rates less than approximately
$2.2 \%(0.148 \times 0.148)$; with four replicate leaves, approximately 1 in every 2,000 susceptible accessions would escape infection.

Variation in single-isolate downy mildew severity within and between Vitis spp. Detached-leaf screening was repeated in 2007 with a new isolate for a subset of arbitrarily selected accessions to assess reproducibility of results. Ratings were consistent (within three gradations) with those from 2006 for 194 of 205 (94.6\%) accessions. All discrepancies resulted from higher disease severity ratings in 2006. The frequency of escapes for the fourth leaf on all moderately susceptible accessions was 171 of $1,222(14.0 \%)$, similar to the escape frequency calculated for the correlation subset above (14.8\%).

The species with the highest average severity across all tested accessions was $V$. vinifera whereas the lowest severity was observed across accessions of $V$. labrusca, $V$. cinerea, and V. coignetiae (Table 2). V. vinifera, Vitis hybrid, V. riparia, and $V$.

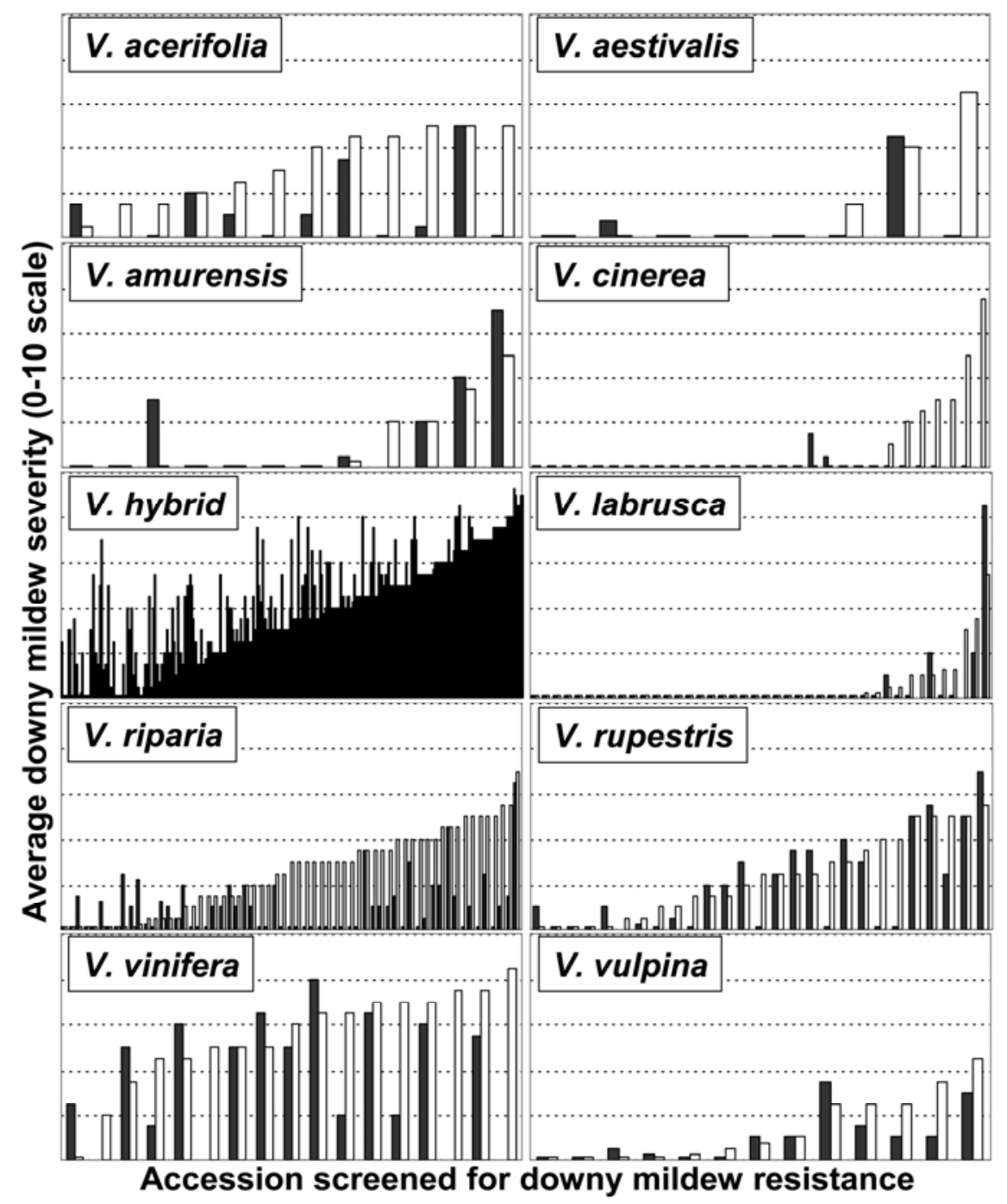

Fig. 2. Downy mildew severity for well-represented species by accession and leaf age. For each accession along the $\mathrm{x}$-axis, filled bars representing younger leaves (second fully expanded leaf in 2006) are coupled with open bars representing older leaves (fourth fully expanded leaf in 2006 and 2007). Accessions are sorted from left to right based on disease severity of older leaves. Interspecific hybrids and taxonomic species with eight or more rated accessions are depicted here. 
labrusca anchored four significantly different categories, ranging from most susceptible to most resistant, respectively (Table 2). However, significant withinspecies variation was observed for most species (Table 3). For example, some accessions of $V$. vinifera repeatedly had low disease severity with little or no sporulation, and some accessions of $V$. labrusca and $V$. cinerea were highly susceptible, with some of the most severe sporulation observed (Table 2; Fig. 2). In fact, with the exception of $V$. vinifera and $V$. acerifolia, for each the 14 species with at least three accessions screened there were accessions that had no sporulation on any replicate leaves (Fig. 2). Therefore, V. labrusca and $V$. cinerea had the lowest average disease severity of the species not only because they comprised resistant accessions but also because most of the accessions in these species were resistant (Table 2).

Age-related resistance. Two ages of leaves were rated in the single-isolate resistance screen in petri dishes. In 2006, second fully expanded leaves frequently died (379 of 2,052) prior to downy mildew rating compared with fourth leaves (44 of $2,052)$. Because of high mortality of the second leaf in petri dishes, only fourth fully expanded leaves were inoculated in
2007. On average across all accessions tested, the increased susceptibility of older leaves (average severity $=2.9$ ) relative to younger leaves (1.8) was highly significant $(P<0.0001$; Table 2). This was exemplified by $V$. acerifolia, $V$. cinerea, $V$. hybrid, and $V$. riparia. Once again, however, this generalization was not true for all accessions, some of which appeared to have more susceptible younger leaves (e.g., PI 588488 and 588334; Table 1).

Cross-study comparison of ratings. For 64 named cultivars and 25 accessions of wild species previously screened for resistance and categorized as resistant, moderate, or susceptible, ratings infrequently corresponded among the previous studies (31.9\%), between the previous studies and single-isolate inoculations ( $34.9 \%)$, between previous studies and current vineyard ratings (46.4\%), and between previous studies and all current data (37.3\%). As examples of the lack of concordance, named cultivars rated in at least three studies are summarized in Table 4, and data for all accessions of wild species tested in multiple studies are provided in Table 5.

\section{DISCUSSION}

Around the world, Vitis germplasm repositories provide an excellent resource for identifying and introgressing new sources of resistance. However, aside from allowing epidemics to develop in the repository and compromise grapevine health and survival, there are no simple approaches to screening for resistance that fully correspond with field ratings. In addition, field ratings for a given accession often vary from one study to another. Here, two approaches were applied for screening diverse accessions of cold-hardy Vitis spp. for resistance to grape downy mildew: natural infection in a replicated, experimental vineyard and single-isolate inoculations on detached leaves. Of the subset that was screened with both approaches, several accessions (16.2\%) were resistant to the single isolate but susceptible in the vineyard. For the remaining accessions, there was a reasonably good correlation between single-isolate inoculations of older leaves and vineyard ratings $(r=0.62$ to 0.71$)$. This suggests that preliminary screens to identify resistant accessions could be conducted on detached leaves and these results subsequently confirmed in more natural conditions.

A number of studies have tested and applied various strategies for quantifying resistance to $P$. viticola, including dualculturing of the pathogen with in vitro

Table 4. Downy mildew resistance ratings for named cultivars of Vitis species screened in at least three studies

\begin{tabular}{|c|c|c|c|c|c|c|c|c|}
\hline Cultivar & $\mathbf{P I}^{\mathrm{s}}$ & $C-D^{t}$ & Brown $^{u}$ & Datar $^{v}$ & Demaree $^{w}$ & Patil $^{x}$ & Sohi $^{y}$ & $\operatorname{Wan}^{\mathbf{z}}$ \\
\hline Concord & 588077 & $\mathrm{R} /-$ & M & $\ldots$ & $\mathrm{R}$ & $\mathrm{R}$ & $\ldots$ & $\ldots$ \\
\hline Lomanto & 588172 & $\mathrm{R} /-$ & M & $\ldots$ & $\mathrm{S}$ & $\ldots$ & $\ldots$ & $\ldots$ \\
\hline Westfield & 588131 & $\mathrm{R} /-$ & M & M & $\ldots$ & $\ldots$ & M & $\ldots$ \\
\hline Athens & 588158 & $\mathrm{R} /-$ & $\mathrm{S}$ & M & $\ldots$ & $\mathrm{R}$ & $\mathrm{S}$ & $\ldots$ \\
\hline Catawba & 588070 & $\mathrm{R} / \mathrm{S}$ & $\ldots$ & $\ldots$ & $\mathrm{S}$ & $\mathrm{R}$ & $\ldots$ & $\ldots$ \\
\hline Lutie & 588658 & $\mathrm{M} / \mathrm{R}$ & $\mathrm{R}$ & $\ldots$ & $\mathrm{R}$ & $\ldots$ & $\ldots$ & $\ldots$ \\
\hline Diamond & 588120 & M/- & M & $\ldots$ & $\mathrm{R}$ & $\ldots$ & $\ldots$ & $\ldots$ \\
\hline Ontario & 588074 & M/- & M & $\ldots$ & $\mathrm{S}$ & $\ldots$ & $\ldots$ & $\ldots$ \\
\hline Cottage & 588576 & M/- & $\mathrm{R}$ & $\ldots$ & $\mathrm{R}$ & $\ldots$ & $\ldots$ & $\ldots$ \\
\hline Ives & 588110 & M/- & M & $\ldots$ & M & $\ldots$ & $\ldots$ & $\ldots$ \\
\hline Clinton & 588303 & $\mathrm{~S} / \mathrm{M}$ & M & $\ldots$ & $\mathrm{R}$ & $\ldots$ & $\ldots$ & $\ldots$ \\
\hline Brighton & 597201 & S/- & M & $\ldots$ & S & $\ldots$ & $\ldots$ & $\ldots$ \\
\hline America & 588119 & S/- & M & $\ldots$ & $\mathrm{R}$ & $\ldots$ & $\ldots$ & $\ldots$ \\
\hline Suelter & 588256 & S/- & M & $\ldots$ & $\mathrm{R}$ & $\ldots$ & $\ldots$ & $\ldots$ \\
\hline Loretto & 588659 & S/- & $\mathrm{R}$ & $\ldots$ & $\mathrm{R}$ & $\ldots$ & $\ldots$ & $\ldots$ \\
\hline Manito & 588302 & S/- & $\mathrm{S}$ & $\ldots$ & $\mathrm{R}$ & $\ldots$ & $\ldots$ & $\ldots$ \\
\hline Captivator & 588159 & S/- & $S$ & $\ldots$ & $\mathrm{S}$ & $\ldots$ & $\ldots$ & $\ldots$ \\
\hline St. George & 588331 & S/- & $\ldots$ & $\ldots$ & $\ldots$ & $\mathrm{R}$ & $\mathrm{R}$ & $\ldots$ \\
\hline Goethe & 588279 & $-/ \mathrm{S}$ & M & M & M & $\mathrm{R}$ & $\ldots$ & $\ldots$ \\
\hline Isabella & 588207 & $-/ \mathrm{S}$ & $\mathrm{R}$ & M & M & $\mathrm{R}$ & $\mathrm{S}$ & $\ldots$ \\
\hline Campbell Early & 588122 & $\ldots$ & $\mathrm{M}$ & $\ldots$ & $\mathrm{S}$ & $\ldots$ & $\ldots$ & $\mathrm{R}$ \\
\hline
\end{tabular}

${ }^{\mathrm{s}} \mathrm{PI}=$ plant introduction number, a unique identifier for each accession in the Germplasm Resources Information Network database, where PI is linked with additional information related to that accession (http://www.ars-grin.gov/npgs/index.html).

${ }^{t}$ Data from the current study (C-D = Cadle-Davidson), with the rating of the fourth detached leaf given first and that for natural infection listed second. Ratings were categorized for detached leaves as follows: less than $1.5=$ resistant $(\mathrm{R})$; from 1.5 to $3.4=$ moderate $(\mathrm{M})$; 3.5 or greater $=$ susceptible $(\mathrm{S})$; and no data $=-$. For natural infection, ratings were categorized as follows: less than $2.5=\mathrm{R}$; from 2.5 to $4.4=\mathrm{M}$; 4.5 or greater $=\mathrm{S}$; and no data $=-$.

u Brown et al. (3) provided ratings of resistant (R), moderately resistant (M), and susceptible (S) from natural infection in a fourfold replicated vineyard in Clarksville, AR. Data were presented for 2 years; here, the more susceptible rating of the 2 years is provided.

${ }^{v}$ Datar (5) inoculated grapevines in a fivefold replicated vineyard in Parbhani, Maharashtra, India from 1979 to 1981 and identified resistant (R) and moderately susceptible $(\mathrm{M})$ individuals.

${ }^{w}$ Demaree et al. (6) allowed natural infection to occur in a vineyard in Washington, D.C. in 1937 and provided ratings on percent coverage of sporulation. Ratings were categorized as follows: $10 \%$ or less $=$ resistant $(\mathrm{R}), 15-30 \%=$ moderate $(\mathrm{M})$, and more than $30 \%=$ susceptible $(\mathrm{S})$.

${ }^{x}$ Patil et al. $(18,19)$ reported summaries of natural infections occurring in a vineyard in Hol (Pune), Maharashtra, India from 1982 to 1988. Only resistant (R) accessions were reported.

${ }^{y}$ Sohi and Sridhar (25) in Hessaraghatta, Mysore, India in 1969 observed natural infection on up to 20 vines per accession and summarized ratings as resistant (R), moderately susceptible (M), susceptible (S), and highly susceptible (S).

${ }^{\mathrm{z}}$ Wan et al. (29) evaluated resistance to natural infections in a vineyard in Yangling, Shaanxi, China, from 2001 to 2003, identifying individuals as highly resistant, resistant (R), susceptible, and highly susceptible. 
plantlets (2), inoculation of single-node cuttings (16), or inoculation of detached leaf discs $(4,27)$. One detailed study compared artificial inoculation of leaf discs or greenhouse plants with natural infections in a nursery vineyard, using ratings for sporulation, chlorosis, and necrosis (4). Sporulation ratings of leaf discs and vineyard plants correlated well $(r=0.47$ to $0.67)$, similar to the current study. In addition, sporulation following artificial inoculations (leaf discs or greenhouse) correlated better with all vineyard ratings than necrosis or chlorosis did (4). Another study confirmed the correlation of leaf disc ratings with those in the vineyard or greenhouse but cited higher disease severity for leaf discs of some resistant accessions (27).

A number of previous studies have screened diverse germplasm for resistance to grapevine downy mildew, including studies focused primarily on interspecific hybrids $(5,6)$, wild species $(10,26)$, or both $(3,18,19)$. In most of the studies involving wild species, a single accession was used to represent each wild species and the identity of that accession was not provided, eliminating the possibility of crossstudy comparisons. However, Staudt and Kassemeyer (26) screened leaf discs of multiple accessions per species, identified intraspecific variation, and provided identification for some of the accessions tested, enabling ratings comparisons with the current data set. In both that study and the current study, no resistance was identified in $V$. acerifolia, and resistant accessions were most frequently identified in $V$. cinerea. For nearly all of the 89 cultivars screened in this and previous studies, ratings infrequently corresponded among previous studies $(31.9 \%)$ and between the current and previous studies (37.3\%). For cultivars rated in the United States and abroad, Vitis hybrid Concord remains the only cultivar consistently resistant $(6,19)$ or moderately resistant (3), suggesting a broad-spectrum, durable foliar resistance rarely found in cultivated Vitis spp.

For the remaining accessions, the effect of pathogen source on resistance ratings could reflect genetic variation in $P$. viticola for overcoming race-specific resistance, which is indirectly supported by data in the current study. Of the 74 accessions (16.2\%) rated for both natural and singleisolate resistance, 12 were resistant to single-isolate inoculation but at least moderately susceptible to naturally occurring, virulent isolates in the vineyard (Table 1; Fig. 1). An individual detached leaf could have no disease severity either by being resistant or by randomly failed inoculation (an escape). Individuals at least moderately susceptible did escape infection in the detached-leaf screen on $14.8 \%$ of inoculated leaves. At this escape rate, detached leaves would randomly escape infection on two, three, or four leaves with a frequency of $2.0,0.32$, or $0.04 \%$, respectively. These 12 accessions with putative race-specific resistance were rated on an average of 2.9 replicate leaves; thus, the lack of disease severity in these individuals was much more likely due to resistance against the single isolates screened rather than escapes.

One accession of $V$. cinerea (PI 588210) was highly resistant in the vineyard (average severity $=0.7$ ) but susceptible to detached-leaf inoculation (average severity = 7.5). Hydrophobic leaf hairs of $V$. cinerea and other wild species reduce access of water droplets harboring downy mildew sporangia to stomatal infection sites (14). Although the identity of accessions used in that study was not provided, when the leaf hair defense was overcome by addition of a detergent, other resistance factors prevented colonization in $V$. cinerea (15). Secondary resistance factors were similarly present in an accession of $V$. labrusca but not in accessions of $V$. davidii or Vitis $\times$ doaniana, which were susceptible when detergents were used to bypass leaf hairs (15). If the physical force of our spray inoculation of detached leaves allowed the sporangia to bypass leaf hairs, this suggests that PI 588210 and moderately susceptible Vitis $\times$ doaniana PI 588149 lack additional resistance factors present in other accessions of $V$. cinerea and $V$. labrusca in Table 1. These results imply that

Table 5. Downy mildew resistance ratings for accessions of wild Vitis spp. screened in multiple locations

\begin{tabular}{|c|c|c|c|c|}
\hline Species, PIw & Accession name & Previous study & Previous rating & Cadle-Davidson ${ }^{\mathrm{z}}$ \\
\hline \multicolumn{5}{|c|}{ Vitis acerifolia } \\
\hline 318684 & $\ldots$ & Brown & M & $\mathrm{S} /-$ \\
\hline 588378 & $\ldots$ & Brown & M & $\mathrm{M} /-$ \\
\hline 588144 & $\ldots$ & Staudt & $\mathrm{R}$ & $\mathrm{S} /-$ \\
\hline \multicolumn{5}{|c|}{ Vitis $\times$ andersonii } \\
\hline 588392 & $\ldots$ & Brown & M & $\mathrm{S} / \mathrm{M}$ \\
\hline \multicolumn{5}{|c|}{ Vitis $\times$ champinii } \\
\hline 483190 & $\ldots$ & Brown & $\mathrm{R}$ & $\mathrm{M} /-$ \\
\hline \multicolumn{5}{|l|}{$V$. cinerea } \\
\hline 588205 & & Brown & M & $\mathrm{S} /-$ \\
\hline 588134 & Ill 45 & Staudt & $\mathrm{R}$ & $\mathrm{R} /-$ \\
\hline 588154 & B 9 & Staudt & $\mathrm{R}$ & $\mathrm{R} /-$ \\
\hline 588217 & B 27 & Staudt & $\mathrm{R}$ & $\mathrm{R} /-$ \\
\hline 597232 & Ill 23 & Staudt & $\mathrm{R}$ & $\mathrm{R} /-$ \\
\hline \multicolumn{5}{|c|}{ Vitis $\times$ doaniana } \\
\hline 588149 & $\ldots$ & Brown & $\mathrm{S}$ & $\mathrm{M} / \mathrm{R}$ \\
\hline 588149 & $\ldots$ & Staudt & $\mathrm{R}$ & $\mathrm{M} / \mathrm{R}$ \\
\hline \multicolumn{5}{|l|}{ V. labrusca } \\
\hline 588182 & GBC 17 & Brown & M & $\mathrm{R} /-$ \\
\hline 483133 & Rem NE 19 & Staudt & $\mathrm{R}$ & $\mathrm{R} /-$ \\
\hline \multicolumn{5}{|l|}{ V. palmata } \\
\hline 588201 & $\ldots$ & Brown & M & $\mathrm{M} / \mathrm{R}$ \\
\hline 588201 & $\ldots$ & Staudt & $\mathrm{R}$ & $\mathrm{M} / \mathrm{R}$ \\
\hline 588155 & RU-66-10 & Staudt & $\mathrm{R}$ & $\mathrm{S} /-$ \\
\hline \multicolumn{5}{|l|}{ V. riparia } \\
\hline 588262 & 89 & Brown & $\mathrm{S}$ & $\mathrm{S} / \mathrm{S}$ \\
\hline 483181 & Rem NE 22 & Staudt & $\mathrm{R}$ & $\mathrm{S} /-$ \\
\hline \multicolumn{5}{|l|}{ V. rupestris } \\
\hline 588160 & B 38 & Brown & $\mathrm{S}$ & $\mathrm{R} / \mathrm{R}$ \\
\hline \multicolumn{5}{|l|}{ V. thunbergii } \\
\hline 588452 & $\ldots$ & Brown & $\mathrm{R}$ & $-/ \mathrm{R}$ \\
\hline \multicolumn{5}{|l|}{ Vitis sp. } \\
\hline 588282 & $\ldots$ & Brown & $\mathrm{R}$ & M/- \\
\hline \multicolumn{5}{|l|}{ V. vulpina } \\
\hline 483184 & Rem 29-77 & Staudt & $\mathrm{R}$ & $\mathrm{R} /-$ \\
\hline \multicolumn{5}{|c|}{ V. yenshanensis } \\
\hline 588421 & $\ldots$ & Brown & $\mathrm{S}$ & $\mathrm{S} / \mathrm{S}$ \\
\hline
\end{tabular}

${ }^{\mathrm{w}} \mathrm{PI}=$ plant introduction number, a unique identifier for each accession in the Germplasm Resources Information Network (GRIN) database, where PI is linked with additional information related to that accession (http://www.ars-grin.gov/npgs/index.html). Two accessions (588149 and 588201) were rated in all three studies.

$x$ Name listed for each accession, provided in the GRIN database.

${ }^{y}$ Brown et al. (3) provided ratings of resistant (R), moderately resistant (M), and susceptible (S) from natural infection in a fourfold replicated vineyard in Clarksville, AR. Data were presented for 2 years; here, the more susceptible rating of the 2 years is provided. Staudt and Kassemeyer (26) inoculated sevenfold replicated leaf discs with a population (H. H. Kassemeyer, personal communication) of Plasmopara viticola collected in Freiburg, Germany and listed resistant (R) accessions, defined by the lack of sporangiophores at 4 days post inoculation.

${ }^{\mathrm{z}}$ Data from the current study with the rating of the fourth detached leaf given first and that for natural infection listed second. Ratings were categorized for detached leaves as follows: less than $1.5=$ resistant $(\mathrm{R})$, from 1.5 to $3.4=$ moderate $(\mathrm{M}), 3.5$ or greater $=$ susceptible $(\mathrm{S})$, and no data $=-$. For natural infection, ratings were categorized as follows: less than $2.5=\mathrm{R}$, from 2.5 to $4.4=\mathrm{M}, 4.5$ or greater $=\mathrm{S}$, and no data $=-$. 
other accessions of these species susceptible to single-isolate inoculations may be resistant to natural infection in the vineyard.

Data from the current study highlight important factors for downy mildew resistance screens: the fourth fully expanded leaf corresponds well with vineyard ratings; pathogen genotype may affect resistance phenotype; and, although some Vitis spp. may be more resistant than others on average, most Vitis spp. have both resistant and susceptible accessions. In addition, for grape breeding programs interested in broad-spectrum resistance, the lack of correspondence between downy mildew resistance screens highlights the importance of confirming resistance across multiple geographic regions with the use of uniform testing procedures.

\section{ACKNOWLEDGMENTS}

This research was supported by USDA-ARS CRIS Project 1910-21220-002-00D at the Grape Genetics Research Unit and by two grants from the USDA-ARS Germplasm Evaluation Program. The ARS-PGRU and Cornell Fredonia Vineyard Laboratory are acknowledged for vineyard maintenance and coordination of sample and data collection. I thank N. Consolie, who helped establish the highthroughput screening protocols; J. Daeffler, M. Hannan, J. D'Amato, and N. Consolie for technical support in collecting, sterilizing, plating, tracking, inoculating, and rating the leaves, a process that involved over 45,000 sample touches for this project; F. Vermeylen for statistical consulting; B. Reisch and P. Cousins for intellectual discussions related to the PGRU germplasm collection; and B. Reisch for critical review of the manuscript.

\section{LITERATURE CITED}

1. Alleweldt, G., and Possingham, J. V. 1988. Progress in grapevine breeding. Theor. Appl. Genet. 75:669-673.

2. Barlass, M., Miller, R. M., and Antcliff, A. J. 1986. Development of methods for screening grapevines for resistance to infection by downy mildew.1. Dual culture in vitro. Am. J. Enol. Viticult. 37:61-66.

3. Brown, M. V., Moore, J. N., Fenn, P., and McNew, R. W. 1999. Evaluation of grape germplasm for downy mildew resistance. Fruit Var. J. 53:22-29.

4. Brown, M. V., Moore, J. N., Fenn, P., and McNew, R. W. 1999. Comparison of leaf disk, greenhouse, and field screening procedures for evaluation of grape seedlings for downy mildew resistance. Hortscience 34:331-333.

5. Datar, V. V. 1986. Sources of resistance in grapevine against downy mildew caused by Plasmopara viticola. Indian Phytopathol.
39:120-122.

6. Demaree, J. B., Dix, I. W., and Magoon, C. A. 1937. Observations on the resistance of grape varieties to black rot and downy mildew. P. Am. Soc. Hortic. Sci. 35:451-460.

7. Di Gaspero, G., Cipriani, G., Adam-Blondon, A. F., and Testolin, R. 2007. Linkage maps of grapevine displaying the chromosomal locations of 420 microsatellite markers and 82 markers for R-gene candidates. Theor. Appl. Genet. 114:1249-1263.

8. Eibach, R., Zyprian, E., Welter, L., and Topfer, R. 2007. The use of molecular markers for pyramiding resistance genes in grapevine breeding. Vitis 46:120-124.

9. Gisi, U., Waldner, M., Kraus, N., Dubuis, P. H., and Sierotzki, H. 2007. Inheritance of resistance to carboxylic acid amide (CAA) fungicides in Plasmopara viticola. Plant Pathol. 56:199-208.

10. He, P. C., and Wang, G. Y. 1986. Studies on the resistance of wild Vitis species native to China to downy mildew, Plasmopara viticola (Berk. et Curtis) Berl. et de Toni. Acta Hortic. Sin. 13:17-24.

11. Holub, E. B., Beynon, L. J., and Crute, I. R. 1994. Phenotypic and Genotypic Characterization of interactions between isolates of $\mathrm{Per}$ onospora parasitica and accessions of Arabidopsis thaliana. Mol. Plant-Microbe Interact 7:223-239.

12. Kast, W. K., Stark-Urnau, M., Seidel, M., and Gemmrich, A. R. 2001. Inter-isolate variation of virulence of Plasmopara viticola on resistant vine varieties cited 3/3 2008. Available from http://www.landwirtschaft-mlr.badenwuerttemberg.de/servlet/PB/menu/1043201_11/ index.html.

13. Kennelly, M. M., Gadoury, D. M., Wilcox, W. F., Magarey, P. A., and Seem, R. C. 2007. Primary infection, lesion productivity, and survival of sporangia in the grapevine downy mildew pathogen Plasmopara viticola. Phytopathology 97:512-522.

14. Kortekamp, A., Wind, R., and Zyprian, E. 1999. The role of hairs on the wettability of grapevine (Vitis spp.) leaves. Vitis 38:101-105.

15. Kortekamp, A., and Zyprian, E. 1999. Leaf hairs as a basic protective barrier against downy mildew of grape. J. Phytopathol. 147:453-459.

16. Liu, S. M., Sykes, S. R., and Clingeleffer, P. R. 2003. A method using leafed single-node cuttings to evaluate downy mildew resistance in grapevine. Vitis 42:173-180.

17. Mahanil, S., Reisch, B. I., Owens, C. L., Thipyapong, P., and Laosuwan, P. 2007. Resistance gene analogs from Vitis cinerea, Vitis rupestris, and Vitis hybrid Horizon. Am. J. Enol. Viticult. 58:484-493.

18. Patil, S. G., Honrao, B. K., Rao, V. G., and Patil, V. P. 1989. Evaluation of grape germplasm for downy mildew resistance and its significance in breeding. Indian J. Hortic. 46:476-479.
19. Patil, S. G., Honrao, B. K., Rao, V. G., and Patil, V. P. 1990. Screening of grape (Vitis species) germplasm for resistance to 3 major fungal diseases. Indian J. Agric. Sci. 60:836-838.

20. Pavlousek, P. 2006. Evaluation of resistance to downy mildew in grapevine genetic resources. Acta Univ. Agric. Silvic. Brno Rada A 54:99106.

21. Pearson, R. C., and Goheen, A. C. 1988. Compendium of Grape Diseases. American Phytopathological Society Press, St. Paul, MN.

22. Postman, J., Hummer, K., Stover, E., Krueger, R., Forsline, P., Grauke, L. J., Zee, F., AyalaSilva, T., and Irish, B. 2006. Fruit and nut genebanks in the US National Plant Germplasm System. Hortscience 41:1188-1194.

23. Reisch, B. I., and Pratt, C. 1996. Grapes. In: Fruit Breeding, Volume II: Vine and Small Fruit Crops. J. Janick and J. N. Moore, eds. John Wiley \& Sons, Inc.

24. Sackston, W. E. 1992. On a treadmillbreeding sunflowers for resistance to disease. Annu. Rev. Phytopathol. 30:529-551.

25. Sohi, H. S., and Sridhar, T. S. 1970. Relative resistance and susceptibility of different grape varieties against downy mildew (Plasmopara viticola Berk. and Curt.) and rust (Phakopsora ampelopsides Diet.) diseases. Indian J. Hortic. 27:57-59.

26. Staudt, G., and Kassemeyer, H. H. 1995. Evaluation of downy mildew resistance in various accessions of wild Vitis species. Vitis 34:225-228.

27. Stein, U., Heintz, C., and Blaich, R. 1985. The in vitro examination of grapevines regarding resistance to powdery and downy mildew. Z. Pflanzenkrankh. Pflanzenschutz 92:355-369.

28. USDA-ARS National Plant Germplasm System. 2008. Germplasm Resources Information Network-(GRIN) Beltsville, Maryland, cited April 28, 2008. Available from http://www.arsgrin.gov/npgs/index.html.

29. Wan, Y. Z., Schwaninger, H., He, P. C., and Wang, Y. J. 2007. Comparison of resistance to powdery mildew and downy mildew in Chinese wild grapes. Vitis 46:132-136.

30. Welter, L. J., Gokturk-Baydar, N., Akkurt, M. Maul, E., Eibach, R., Topfer, R., and Zyprian, E. M. 2007. Genetic mapping and localization of quantitative trait loci affecting fungal disease resistance and leaf morphology in grapevine (Vitis vinifera L). Mol. Breed. 20:359374.

31. Wong, F. P., and Wilcox, W. F. 2001. Comparative physical modes of action of azoxystrobin, mancozeb, and metalaxyl against Plasmopara viticola (grapevine downy mildew). Plant Dis. 85:649-656.

32. Wroblewski, T., Piskurewicz, U., Tomczak, A., Ochoa, O., and Michelmore, R. W. 2007. Silencing of the major family of NBS-LRRencoding genes in lettuce results in the loss of multiple resistance specificities. Plant $\mathrm{J}$. 51:803-818. 